\title{
Functionally graded structures of refractory metals by Wire Arc Additive Manufacturing
}

\author{
Gianrocco Marinelli*, a ${ }^{2}$ Filomeno Martina ${ }^{\mathrm{a}}$, Supriyo Ganguly ${ }^{\mathrm{a}}$, Stewart \\ Williams ${ }^{a}$, Heather Lewtas ${ }^{b}$, David Hancock ${ }^{b}$ \\ ${ }^{a}$ Welding Engineering and Laser Processing Centre (WELPC), Cranfield University, Cranfield, \\ MK43 OAL, United Kingdom \\ ${ }^{b}$ United Kingdom Atomic Energy Authority, Culham Centre for Fusion Energy, Culham Science \\ Centre, Abingdon, OX14 3DB, United Kingdom
}

*Corresponding Author. E-mail address: g.marinelli@cranfield.ac.uk (G. Marinelli)

\begin{abstract}
Address: Welding Engineering and Laser Processing Centre (WELPC), College Road, Cranfield University, Cranfield,

MK43 OAL, United Kingdom
\end{abstract}

\begin{abstract}
Functionally graded components are usually preferred for severe and critical service conditions, thanks to the possibility of achieving different complimentary material properties within the same structure. Wire + Arc Additive Manufacturing is an emerging technology which lends itself well to the production of sound graded structures. In this study, an integral structure of two functional gradients, namely tantalum to molybdenum, and molybdenum to tungsten, was successfully deposited. A linear gradient was observed in both composition and hardness. Microstructure, elemental composition and hardness were characterised as a function of position, and discussed. The study demonstrates that WAAM has the potential to successfully deposit functionallygraded structures of refractory metals, obtaining controlled properties.
\end{abstract}

Keywords: WAAM, Additive Manufacturing, Functionally Graded Structure, Refractory Metals, Microstructure, Hardness, Chemical Analysis.

\section{Introduction}

Functionally graded structures (FGSs) are advanced and highly-functional regions within a component; they present a localised continuous variation of chemical composition and, usually, microstructures which lead to innovative and tailored mechanical or thermal responses [1]. This spatial gradient can be completely custom-made for specific performances or functions [2].

The term "functionally graded material" was originally introduced in Japan in 1984, when the development of thermal barrier coating was studied [3]. The need for graded material arises in order to replace the sharp transition occurring when two materials are interfaced, with a gradient that produces smooth changeover from one material to the next [4]. Extreme-environmental applications require components that can provide exceptional performances when, for instance, different stress fields are localized at different positions 
within the same part. For this reason, these critical components would benefit from graded properties and complementary microstructural features brought about by different alloys.

A very specific example of an extreme environment is that of the nuclear fusion reactor, in which components are affected by substantially different thermal gradients $[5,6]$. Other applications can be, for instance, spacecraft heat shields, heat exchanger tubes, biomedical implants, and flywheels [7]. The manufacture of FGSs also allows new structures, made of ordinarily incompatible materials, finally seen implemented within one structure, effectively creating new material solutions [7]. Typically, materials that have marked differences with regard to physical and chemical properties can be embedded in a single structure [7].

In recent years, great attention has been given to a specific class of graded structures, in particular metal-based functionally graded materials [8]. These can be built not only taking into account the compositional gradient, but also using a microstructural or geometrical gradient of a single-material component. In particular, there have been studies aiming to obtain a gradual change in microstructure [9] produced with local functionalities in crystallographic texture and grain size [10] and others which implement geometrical gradient in functional mesh density [11].

Naebe and Shirvanimoghaddam [12] published a review of different techniques for FGSs production, and their impact on the final properties. Other basic production techniques specific to metal-based structures can be found in the work of Sobczak and Drenchev [8]. In general, there are several manufacturing approaches that enable the required compositional gradient; these include gas phase, liquid phase and solid phase methods [13]. In addition to these techniques, Additive Manufacturing (AM) processes have been extensively covered in the literature as promising and flexible approaches to modulate and control the gradient within multi-material structures.

The study and the implementation of these manufacturing techniques will certainly bring a step-forward to the next-generation of graded structures [12]. The characteristic highaccuracy and process-controllability of AM allow to couple graded composition with challenging geometrical and microstructural features, enabling the production of f.i. high-tech biocompatible prosthesis [12].

Different AM processes and materials have been already studied and characterised within the realm of metal-based functional gradients. In the work of Domack and Baughman [14], three different manufacturing routes were used to produce a graded structure between Inconel 718 and Ti-6Al-4V. In particular, they studied laser metal powder deposition, flat wire welding, and ultrasonic foil consolidation. The structures manufactured in this study presented macroscopic cracking due to the formation of brittle phases. Moreover, FGSs between iron and aluminium have also been produced by Wire + Arc Additive Manufacturing (WAAM) in the study of Shen et al. [15] showing a regular chemical gradient and acceptable mechanical properties. Additional experimental characterization and computational analysis have been conducted for structures with a gradient from Ti-6Al-4V to Invar 36 [16] and from 304L stainless steel incrementally graded to Inconel 625 [17]. Niendorf et al. [9] proved the feasibility of producing stainless steel components with different local functionalities by using selective laser melting (SLM). This was achieved through the manipulation and the control of the microstructure at different build positions. The production of a gradient with regards to the mesh density for high strength and high energy absorption Ti-6Al-4V components has also been studied and produced using electron beam melting (EBM) [11]. Furthermore, some 
studies on residual stress evolution for graded structures were reported in the work of Dao et al. [18] and Cannillo et al. [19].

When analysing these studies, it is possible to asses that the main challenges for the production of graded structures using AM are the concentration of residual stresses, the mismatch of thermo-mechanical properties of the deposited metals and the formation of intermetallics or other brittle phases during the deposition process. Thus, inaccuracy with regards to the process calculation and design specifications can drive to unwanted failures [20].

As already mentioned, an increasing interest with regards to innovative manufacturing techniques of high-performance refractory metal components has arisen from the nuclear sector. This is because refractory metals are primarily characterised by high melting point and density, and therefore are able to withstand the reactor's high temperatures. In fact, molybdenum thermal blankets have been proposed for piping of nuclear systems in the work of Rizakhanov et al. [21]. Additionally, tungsten and its alloys are considered to be the best candidate as plasma-facing materials [22]. However, their brittleness at low temperatures presents a limitation for their use as a structural material [23]. Weber and Aktaa [24] conducted a numerical assessment for graded tungsten-to-steel joints. They estimated that a controlled graded structure between the two metals is necessary for the divertor application in order to overcome their remarkable difference in thermal expansion. They proposed vacuum plasma spraying (VPS) and resistance sintering under ultra-high pressure (RSUHP) as suitable methods for the production of sound tungsten-to-steel FGSs [24]. For all these reasons, the production of components for the high-temperature applications using AM is becoming one of the most ambitious objectives of the nuclear industry.

At present, very few investigations have been reported with regards to the possibility of producing parts in unalloyed tungsten, tantalum and molybdenum using AM methods. Moreover, investigations referring to the functional gradients of such materials within the same components are almost absent. In the present work, graded structures comprising three dissimilar alloys, in particular tantalum, molybdenum and tungsten, were fabricated within the same structure using WAAM. These metals were deposited in their unalloyed form using a wire feedstock. Fundamental properties common to these three metals are the high melting point, and their complete miscibility without the formation of secondary phases between one another. The aspects for which they differentiate are physical properties such as the coefficient of thermal expansion, thermal conductivity and ductile-to-brittle transition temperature. A unique and robust way of manufacturing a controlled gradient between different refractory metals using a WAAM process is presented. The goal of the current study was to investigate the manufacturing of refractory-metal FGSs and analyse the quality of the formed interfaces by microstructural analysis, by hardness and chemical composition evaluations.

\section{Experimental Procedure}

Two different refractory metals, molybdenum and tungsten were deposited on a tantalum plate to create two functionally graded structures integrally. The overall structure had a height of $10.5 \mathrm{~mm}$, and a width of $8.5 \mathrm{~mm}$. Starting from a tantalum plate, a linear structure was deposited using molybdenum wire initially followed subsequently by a tungsten wire. Both wires had a diameter of $1 \mathrm{~mm}$, and all materials were of high-purity, as shown in Table 1. Some mechanical properties and thermo-physical properties of these metals are also summarised in 
Table 2.

Table 1: Elemental composition (wt.\%) of tungsten wire (W wire), molybdenum wire (Mo wire) and tantalum substrate (Ta sub).

\begin{tabular}{|c|c|c|c|c|c|c|c|c|c|c|c|}
\hline & $\mathbf{w}$ & Mo & $\mathrm{Ta}$ & $\mathrm{Ti}$ & $\mathrm{v}$ & $\mathrm{Cr}$ & $\mathrm{Fe}$ & C & $\mathbf{N}$ & 0 & $\mathrm{~K}$ \\
\hline $\begin{array}{l}\text { W } \\
\text { wire }\end{array}$ & 99.99 & $<0.05$ & $<0.05$ & $<0.05$ & $<0.05$ & $<0.05$ & $<0.05$ & $\begin{array}{c}33 \\
\mathrm{ppm}\end{array}$ & $\begin{array}{l}<10 \\
\mathrm{ppm}\end{array}$ & $\begin{array}{l}<50 \\
\mathrm{ppm}\end{array}$ & $\begin{array}{l}<10 \\
\mathrm{ppm}\end{array}$ \\
\hline $\begin{array}{l}\text { Mo } \\
\text { wire }\end{array}$ & 99.99 & $<0.05$ & $<0.05$ & $<0.05$ & $<0.05$ & $<0.05$ & $<0.05$ & $\begin{array}{c}30 \\
\mathrm{ppm}\end{array}$ & $\begin{array}{l}<10 \\
\mathrm{ppm}\end{array}$ & $\begin{array}{c}59 \\
\mathrm{ppm}\end{array}$ & $\begin{array}{l}<10 \\
\mathrm{ppm}\end{array}$ \\
\hline $\begin{array}{l}\text { Ta } \\
\text { sub }\end{array}$ & 99.99 & $<0.05$ & $<0.05$ & $<0.05$ & $<0.05$ & $<0.05$ & $<0.05$ & $\begin{array}{c}33 \\
\mathrm{ppm}\end{array}$ & $\begin{array}{l}<10 \\
\mathrm{ppm}\end{array}$ & $\begin{array}{c}60 \\
\mathrm{ppm}\end{array}$ & $\begin{array}{l}<10 \\
\mathrm{ppm}\end{array}$ \\
\hline
\end{tabular}

Table 2: Typical values of thermal conductivity $(K)$, melting point $\left(T_{f}\right)$, the coefficient of thermal expansion $(\alpha)$ and elastic modulus (E) for tungsten, molybdenum and tantalum from [25].

\begin{tabular}{ccccc}
\hline & $\begin{array}{c}\mathbf{K} \\
{\left[\mathbf{W m}^{-1} \mathbf{K}^{-1}\right]}\end{array}$ & $\begin{array}{c}\mathbf{T}_{\mathbf{f}} \\
{\left[{ }^{\circ} \mathbf{C}\right]}\end{array}$ & $\begin{array}{c}\boldsymbol{\alpha} \\
{\left[\boldsymbol{\mu} \mathbf{m ~ m}^{-1} \mathbf{K}^{-1}\right]}\end{array}$ & $\begin{array}{c}\mathbf{E} \\
{[\mathbf{G P a}]}\end{array}$ \\
\hline W & 174 & 3422 & 4.5 & 411 \\
Mo & 138 & 2623 & 4.8 & 330 \\
Ta & 57.5 & 3017 & 6.3 & 185 \\
\hline
\end{tabular}

The tantalum plate had a thickness of $4.0 \mathrm{~mm}$; prior to deposition, it was polished in order to remove the oxide layer and rinsed with acetone to remove residues of contaminants. Figure 1 shows the layout of the welding apparatus used in this study. In particular, a conventional tungsten inert gas (TIG) torch, a power supply and a controlled wire feeder were used for the deposition. The heat source, the wire delivery system and the substrate were attached to three linear motorized high-load stages assembled in XYZ configuration. The apparatus was surrounded by a heavy-duty enclosure to ensure a low level of oxygen when purged with argon.

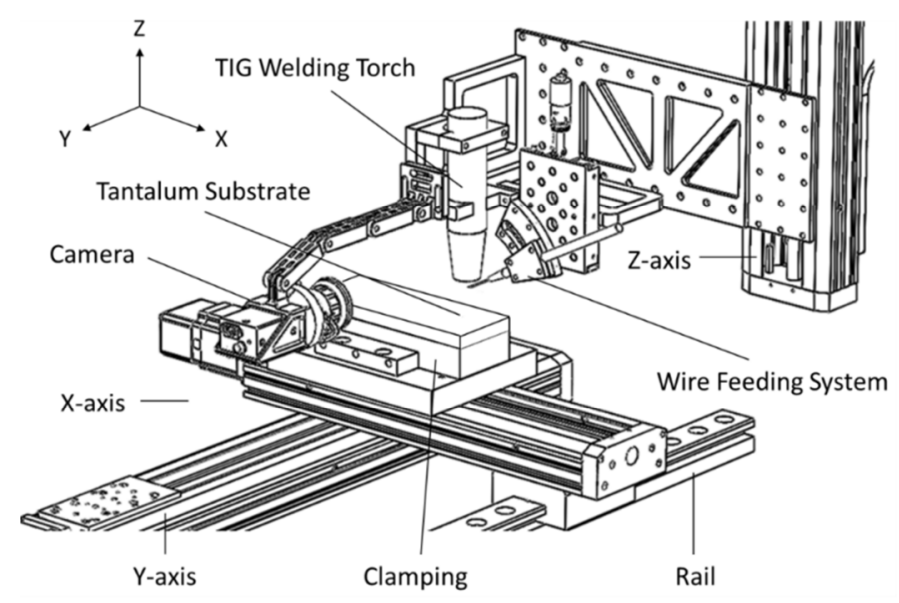

Figure 1: Set-up used for the deposition of refractory metal FGS using the WAAM process. 
Table 3 lists the process parameters that were kept constant during the deposition; this was to limit the process variables investigated. Otherwise, primary process parameters that were changed are reported in Table 4.

The deposition of each successive layer was performed once the substrate had cooled down to room temperature. The cross-section perpendicular to the deposition direction was selected for the characterization. The samples were polished and chemically etched to reveal the microstructures. Murakami's Reagents were used as etchant solution for the investigation of all three alloys.

The hardness of the structure was measured using an automatic hardness testing machine. The indentation load, time and spacing were of $1 \mathrm{~kg}, 15 \mathrm{~s}$, and $100 \mu \mathrm{m}$, respectively.

The chemical composition of the structure deposited was measured using a scanning electron microscope (SEM) equipped with an energy-dispersive spectrometer (EDS), operating at $20 \mathrm{keV}$.

Table 3: Process parameters that were not varied during the deposition.

\begin{tabular}{cc}
\hline Electrode-to-workpiece distance & $3.5 \mathrm{~mm}$ \\
Tungsten electrode tip angle & $45^{\circ}$ \\
Diameter of the electrode & $3.6 \mathrm{~mm}$ \\
Torch shielding gas composition & $100 \% \mathrm{He}$ \\
Shielding gas flow rate & $15 \mathrm{~L} \mathrm{~min}^{-1}$ \\
Oxygen Atmosphere of Deposition & $<100 \mathrm{ppm}$ \\
\hline
\end{tabular}

Table 4: Layer-by-layer parameters breakdown.

\begin{tabular}{ccccc}
\hline $\begin{array}{c}\text { Wire } \\
\text { Material }\end{array}$ & $\begin{array}{c}\text { Layer } \\
\text { Num. }\end{array}$ & $\begin{array}{c}\text { Travel } \\
\text { Speed } \\
\text { (TS) } \\
\text { [mm/s] }\end{array}$ & $\begin{array}{c}\text { Wire Feed } \\
\text { Speed } \\
\text { (WFS)[mm/s] }\end{array}$ & $\begin{array}{c}\text { Current } \\
\text { [A] }\end{array}$ \\
\hline & 1 & 4 & 20 & 300 \\
Molybdenum & 2 & 4 & 20 & 300 \\
Wire & 3 & 4 & 20 & 300 \\
& 5 & 4 & 20 & 300 \\
& 6 & 4 & 20 & 300 \\
& 7 & 4 & 20 & 300 \\
Tungsten & 8 & 4 & 20 & 300 \\
Wire & 11 & 4 & 15 & 300 \\
\hline & 12 & 4 & 15 & 300 \\
& 13 & 3 & 15 & 300 \\
& 14 & 3 & 20 & 300 \\
& 10 & 4 & 20 & 300 \\
\hline
\end{tabular}




\section{Results and Discussion}

\section{Microstructure}

Figure 2 reveals the microstructure of the two FGSs within the integral WAAM deposit. An FGS between tantalum ( $\mathrm{Ta}$ ) and molybdenum (Mo) was located at the bottom, whereas an FGS between molybdenum and tungsten (W) was located towards the middle of the sample's height. Figure 2 also shows the higher-magnification micrographs of some microstructural features present at different spatial positions within the deposited structure, in particular at the interface between the two refractory metals. Figure 2 a reports the microstructure of the whole deposited structure and its characteristic features. In particular, large columnar grains were visible within molybdenum-rich regions; finer equiaxed grains dominated the microstructure of tungsten-rich regions.

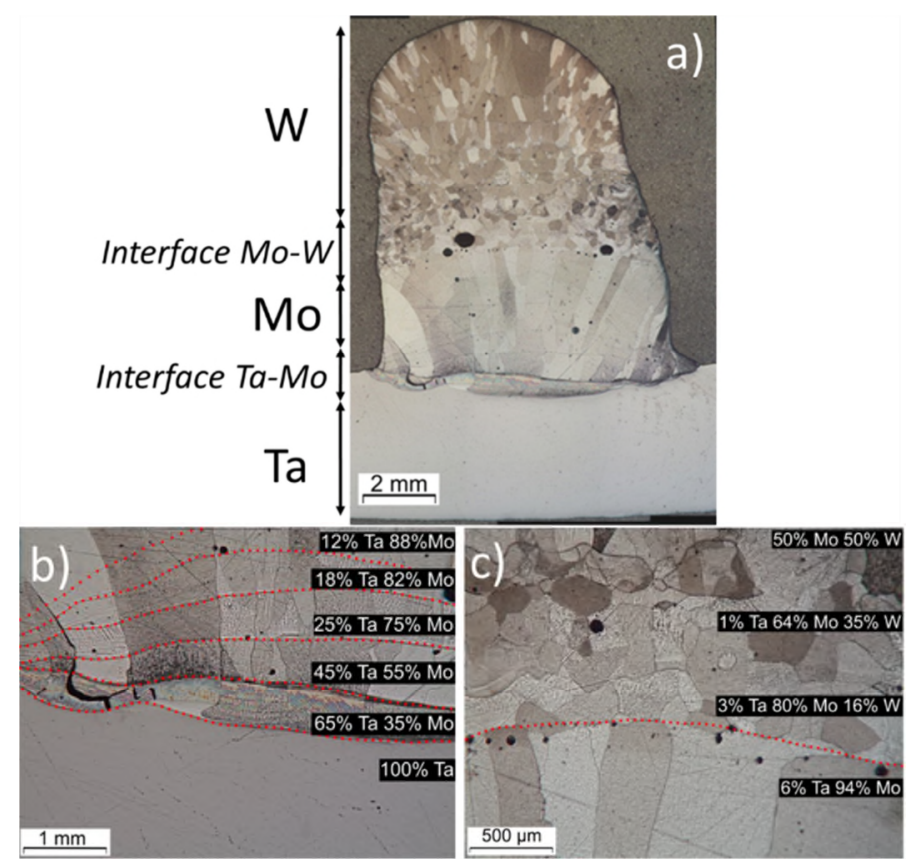

Figure 2: Microstructure of the entire deposited structure (a); Higher magnification micrographs of the tantalum to molybdenum interface $(b)$ and the molybdenum to tungsten interface (c).

With regards to integrity, cracks and porosities were seen at the interfaces between tantalum and molybdenum and molybdenum and tungsten respectively. An impressive absence of cracks could be appreciated at the interface between molybdenum and tungsten. The microstructural evolution and the distribution of the defects throughout the layers can be directly correlated to the material composition seen at different regions.

Figure $\mathbf{2} \mathbf{b}$ shows the microstructural features at the tantalum-molybdenum interface, which consisted of columnar grains with a marked presence of cracks across the grain boundaries. The average non-stoichiometric composition of the first deposited layer of molybdenum resulted to be around $65 \mathrm{wt} . \%$ of tantalum and $35 \mathrm{wt} . \%$ of molybdenum. With the successive depositions of molybdenum, columnar grains developed parallel to the building direction with an increased presence of porosity but a decreased presence of cracks. The characteristic columnar-like microstructure was seen for molybdenum composition ranging from $55 \mathrm{wt} . \%$ to $94 \mathrm{wt} . \%$. When tungsten was introduced in the deposition, the second 
gradient started to form; a noticeable reduction in porosity and a change in microstructure from columnar to equiaxed were seen, with a content of tungsten equal to $15 \mathrm{wt}$.\% (Figure $\mathbf{2 c}$ ).

Columnar grains in components produced by AM have been already reported for tantalum, titanium and nickel alloys [26-30]. These grains usually form from the ones underneath the melt pool, that act as nucleation sites, and grow epitaxially, parallel to the building direction, across multiple layers. This was also the solidification process of molybdenum-rich regions seen in this research. Typically, a finer microstructure can be promoted by faster solidification rates, or by employing a lower heat-input. This could possibly lead to a change in the solidification regime from columnar to equiaxed grains.

In the present research, the addition of tungsten to molybdenum resulted in a metallic solution with an increased melting point and thermal conductivity, with respect to unalloyed molybdenum. Consequently, the liquid solution started to solidify at a higher rate; the heat was extracted from the liquid pool also at a higher rate. Under these conditions, epitaxial grain growth was no longer dominating the solidification; indeed, it was defeated by the heterogeneous nucleation caused by a faster cooling rate. The continuous increase in tungsten content promoted this effect, leading to the formation and growth of finer equiaxed grains. Furthermore, each layer was deposited when the entire structure had cooled to room temperature; this could have enhanced the conditions for heterogeneous nucleation.

A similar phenomenon was seen in the study of Shen et al. [15], who deposited FGSs between iron and aluminium. The major similarity between our and their researches is that a metal with higher thermal conductivity was deposited onto one with lower thermal conductivity. In fact, the thermal conductivities of aluminium and iron are $205 \mathrm{~W} \mathrm{~m}^{-1} \mathrm{~K}^{-1}$ and $80.4 \mathrm{~W} \mathrm{~m}^{-1} \mathrm{~K}^{-1}$, respectively [15]; the values for tungsten and molybdenum are $174 \mathrm{~W} \mathrm{~m}^{-1} \mathrm{~K}^{-1}$ and $138 \mathrm{~W} \mathrm{~m}^{-1} \mathrm{~K}^{-1}$, respectively (Table 2). For this reason, depositing aluminium on iron can be compared to depositing tungsten on molybdenum; in fact, a similar effect was observed with regards to the solidification and the resulting microstructural pattern.

Furthermore, in the work of Reichardt et al. [31], a sharp change from columnar to finer equiaxed grains was reported when depositing a vanadium-rich alloy onto a titanium-rich alloy. The authors explained it with insufficient process heat input, as vanadium has a higher melting point than titanium. As can be seen in Table 4, when going from molybdenum to tungsten, the heat input was kept constant for every layer, excluding the last two layers in tungsten, where the increased melting point had to be compensated by an increased heat input.

The finer microstructure of the tungsten-rich regions could have been produced by the progressively higher melting point of the alloys and the enhanced extraction of the heat, which promoted heterogeneous nucleation against the epitaxial growth.

The causes of the cracks evolution between tantalum and molybdenum is explained by the intense stress fields developed at this particular interface during deposition; and by the critical mechanical mismatch between the two metals, due to their difference in plasticity

(Table 2). Further investigations were carried out in order to verify the presence of compositional or microstructural fluctuations and are reported in the next sections.

\section{Correlation between hardness and chemical composition}

Figure 3 reports the elemental composition and the Vickers hardness profile of the structure as 
a function of the position; the origin is on the top surface of the starting tantalum substrate.

(1) (2)

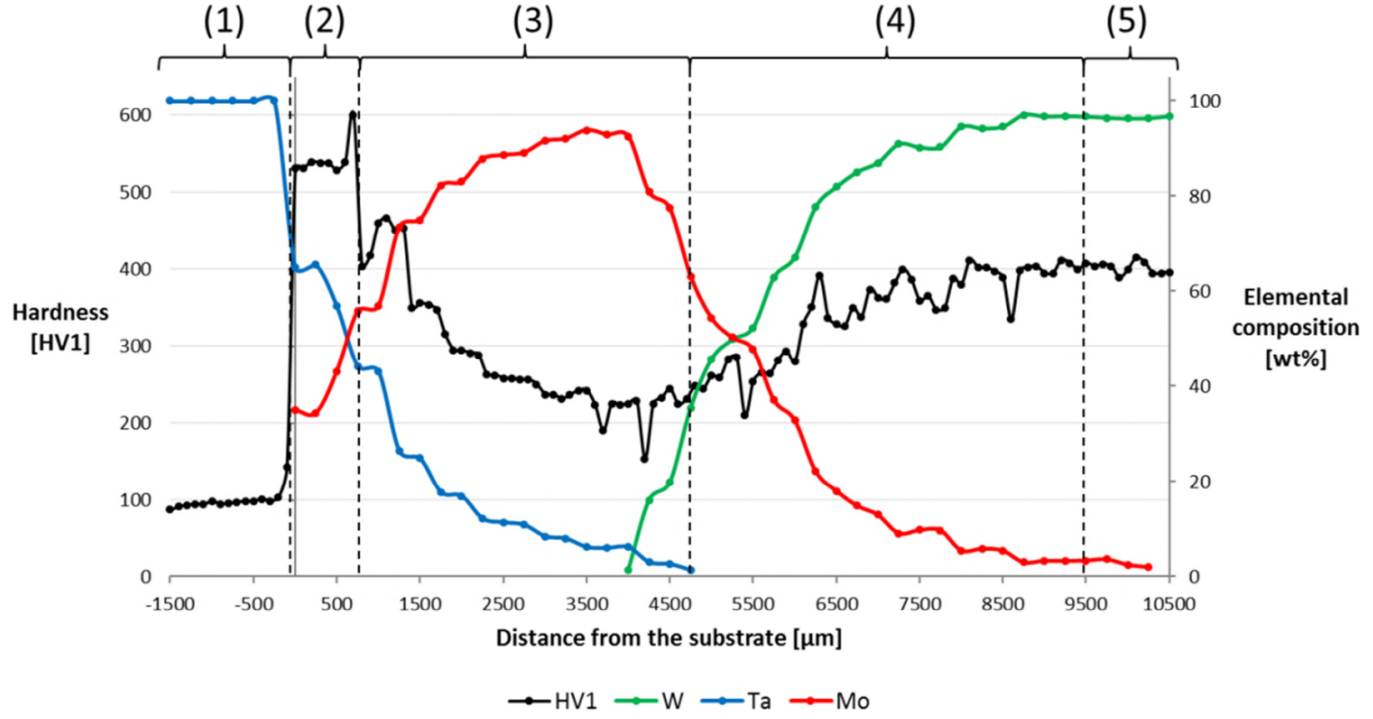

Figure 3: Microhardness (black) of the graded alloys overlaid on tungsten (green), tantalum (blue) and molybdenum (red) composition versus the distance from the substrate top. (1) tantalum substrate, (2) interface tantalum to molybdenum, (3) FGS tantalum to molybdenum, (4) FGS molybdenum to tungsten and (5) almost unalloyed tungsten. All the measurements were taken from the centreline of the structure.

The average measured composition closely matched the hardness profile along the structure. Small progressive plateaus were observed for both composition and hardness; these regions of consistent properties matched the dimensions of each deposited layer. The first FGS, between tantalum and molybdenum, covered about $4 \mathrm{~mm}$ while the second, between molybdenum and tungsten, covered about $5.5 \mathrm{~mm}$.

When depositing a layer, the one previously deposited was only partially melted and, with the addition of the wire feedstock, an alloy with a new composition was formed. The reiteration of this process created a smooth gradient in composition, which could be designed and controlled by varying the process parameters. The re-melting extent and the quantity of added feedstock are the main factors to consider and monitor in order to control the gradient slope and dimension. In fact, the re-melting of the layer is directly connected to the heat input, and to the melting point and thermal properties of the local alloy. The quantity of the material added for the WAAM process is directly connected to the WFS/TS ratio. High WFS/TS ratio leads to a high dilution of the melted layer composition. Thus, the dilution of each layer is directly proportional to the WFS/TS ratio and inversely proportional to the process heat input.

As stated above, the hardness trend along the entire structure matched the compositional gradients. In particular, five main regions of interest can be recognised with regards to the hardness profile (Figure 3 ). The hardness of the tantalum substrate remained constant to an average of $95 \mathrm{HV}$ through the entire substrate thickness. The interface between tantalum and molybdenum was characterised by a sharp increase in hardness to around 550$600 \mathrm{HV}$. No intermetallic phases were formed during the deposition due to their complete solid solubility. Typically, tantalum vigorously decreases its plasticity and increases its hardness when alloyed with a relatively large quantity of tungsten, as reported in the study of Chen and Gray [32]. A similar effect could have verified when the first two layers of molybdenum were 
deposited. For this reason, the presence of numerous cracks is also justified by the marked brittleness of this intermediate metallic solution.

The hardness then constantly decreased within the first FGS until it stabilised around $240 \mathrm{HV}$ for molybdenum-rich regions. With the addition of tungsten, the hardness gradually increased within the FGS between molybdenum and tungsten, until it stabilised around $400 \mathrm{HV}$ within the tungsten-rich regions at the top of the structure. Further investigations using EDS maps and elemental analysis have been performed in order to explain these variations.

\section{EDS maps and chemical analysis}

\section{Interface between tantalum and molybdenum}

Figure 4a-c report the back-scattered electron images and the energy-dispersive spectrometer (EDS) elemental maps for the interface between tantalum and molybdenum. Figure $\mathbf{4 d - f}$ refers to higher magnification scans within the mixing zone located on the first layer.

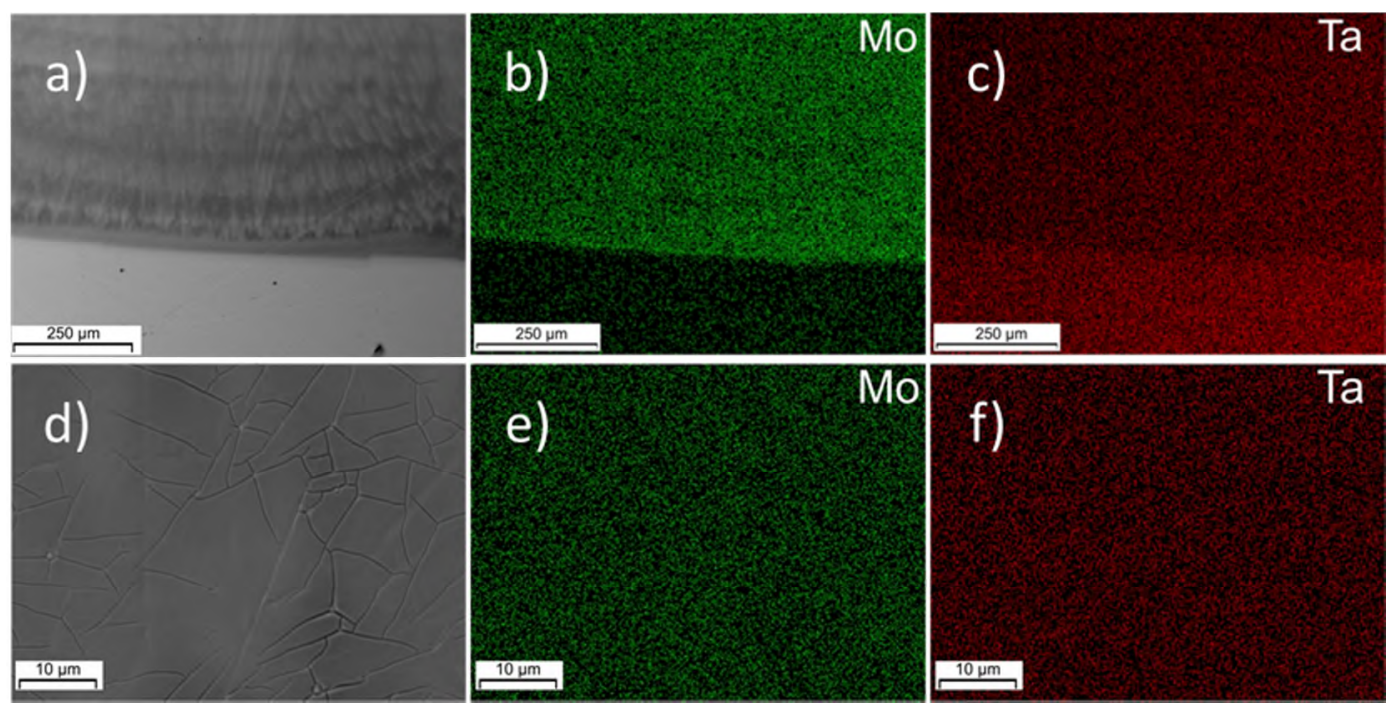

Figure 4: Back-scattered electron images (a)(d) and EDS elemental maps (b-c) (e-f) of the tantalum-molybdenum interface.

A sudden change, in contrast, is reported in Figure 4a, which represents the compositional boundary layer between the first layer of molybdenum and the tantalum substrate. The EDS maps reported in Figure $\mathbf{4 b}$ and Figure $\mathbf{4 c}$ show respectively the distribution of molybdenum and tantalum across the interface. This region was characterised by the presence of cracks and a considerably higher hardness. When analysing this region at higher magnification, a dense network of several hundred micron-long micro-cracks was found, as shown in Figure 4d. From the elemental maps in Figure $\mathbf{4 e}$ and Figure $\mathbf{4 f}$, the crack-rich area was not characterised by any enriched regions or inconsistent compositional variations around the cracks, remarking the structure's heterogeneity.

Some of the physical and thermal properties of both tantalum and molybdenum are reported in Table 2 . From these data, it is possible to notice the considerable differences with regards the coefficient of linear thermal expansion $(\alpha)$ and the elastic modulus (E). In particular, they are respectively $6 \mu \mathrm{m} \mathrm{m}^{-1} \mathrm{~K}^{-1}$ and $170 \mathrm{GPa}$ for tantalum and $4 \mu \mathrm{m} \mathrm{m}^{-1} \mathrm{~K}^{-1}$ and 329 GPa for molybdenum. Weber and Aktaa [24] assessed that the difference in mechanical 
properties is amongst the most critical problems when joining dissimilar metals. Bobbio et al. [16] investigated Ti-6Al-4V to Invar FGS, and argued that a possible cause of severe cracking was the marked difference in the coefficient of thermal expansion of the two metals; this can lead to a high concentration of stresses, after multiple thermal cycles. For these reasons, the large mismatch of thermal and mechanical properties of tantalum and molybdenum can be identified as the principal cause for the occurrence of cracks within the interface between these two metals.

The magnitude of the residual stresses for components deposited via WAAM is usually reported to be considerably high, due to the intrinsic nature of the process. In particular, the interface between deposit and baseplate resulted to be characterised by a larger concentration of residual stresses with compared to the upper layers [33]. At this specific location of the deposit, both longitudinal and transverse components of the residual stress add-up, increasing the local loading of the part [34].

With regards to the case analysed in this study, the development of the dense network of cracks seen at the interface between tantalum and molybdenum was caused by a combined effect of the considerable mismatch between physical and mechanical properties of the metals and the concentration of residual stress at the root of the structure. Besides these factors, the increased hardness and brittleness of the alloy 35Mo65Ta also played a crucial role. The fact that two elements are metallurgically compatible is not sufficient to ensure sound FGS layers.

\section{Molybdenum to tungsten interface}

Back-scattered electron images and EDS elemental maps relative to the FGS between molybdenum and tungsten are shown in Figure 5. The characterisation of variations in composition was conducted for the initially deposited layers of tungsten, in particular, where the average non-stoichiometric composition measured at this position was $80 \mathrm{wt} . \%$ in molybdenum, $16 \mathrm{wt} . \%$ in tungsten and $4 \mathrm{wt} . \%$ in tantalum.

The differences in contrast in the back-scattered electron images are due to a compositional gradient or zoning, instead of surface or grain morphology. molybdenum-rich zones are shown as darker regions than tungsten-rich ones. The contrast reflects the average composition at every point. Therefore, it is possible to notice tungsten-enriched zones located across the layer surrounded by a molybdenum-tungsten matrix, as shown in the elemental maps reported in Figure $\mathbf{5 b}$ and Figure $\mathbf{5 c}$. This phenomenon was observed only for the initial tungsten layers.

In order to quantify and characterise these variations in composition, EDS elemental analysis at multiple zones was performed with different contrast. The location of each acquisition is indicated in Figure $\mathbf{5 d}$. In Table 5, the values of the elemental composition of the four regions examined are listed. It can be seen that the brightest regions were characterised by a composition of $100 \mathrm{wt} . \%$ of tungsten while some surrounding regions were characterised by a tungsten composition as low as $22.0 \mathrm{wt} . \%$. 

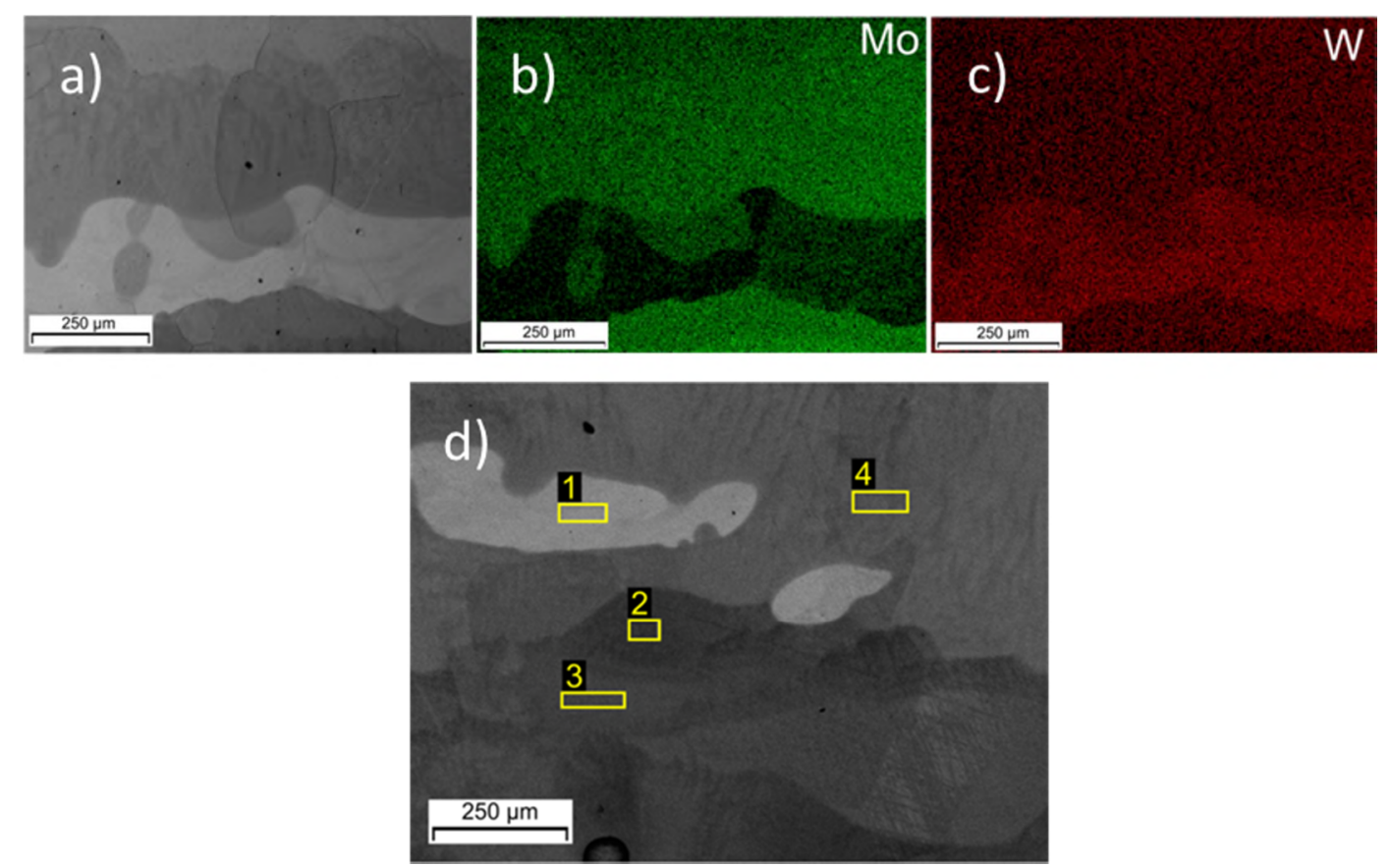

Figure 5: Back-scattered electron image (a) and EDS elemental maps (b-c) for the FGS between molybdenum and tungsten; Back-scattered electron image (d) of the FGS between molybdenum and tungsten.

Table 5: Elemental composition of the local chemical analysis.

\begin{tabular}{cccc}
\hline & Mo & Ta & W \\
& {$[w t . \%]$} & {$[w t . \%]$} & {$[w t . \%]$} \\
\hline Spectrum 1 & & & 100 \\
Spectrum 2 & 75.14 & 2.92 & 21.94 \\
Spectrum 3 & 65.02 & & 34.98 \\
Spectrum 4 & 51.56 & & 48.44 \\
\hline
\end{tabular}

During the deposition of the initial layer using tungsten wire, tungsten-rich regions formed within the structure mainly because of the difference in melting points and thermal conductivities of the two metals (Table 2). Usually, the deposition of each layer by an AM process can be considered to be inherently a non-equilibrium state, because of the rapid solidification of the liquid pool. Furthermore, the difference in density could have also contributed. For this reason, the optimal mixing condition of the two liquid metals, within the weld pool, was not reached and the distribution of the alloying element was not uniform for the initial layers. These localised variations in composition had a noticeable impact on the hardness trend, as shown in Figure 3. The features described were not observed in the 
successive layer mainly due to the increased content of tungsten which facilitated the alloying with molybdenum.

The absence of cracks observed between tungsten and molybdenum was one of the most important features deserving to be highlighted. Contrarily to the FGS between tantalum and molybdenum, the molybdenum-tungsten FGS did not present either micro- or macrocracks within its volume. The two metals are characterised by similar elastic modulus and coefficient of linear thermal expansion (Table 2), which explains the high integrity of the structure, besides full solid solubility.

\section{Conclusions}

In the present work, the deposition of multiple graded structures between tantalum, molybdenum and tungsten was studied. This was one of the first process studies on the deposition of gradients for large-scale refractory metal structures. The Wire + Arc Additive Manufacturing process showed great flexibility and potential with regards to the creation of advanced components through controlled deposition. The microstructure, hardness profile and elemental composition were characterised along the height of the structure. The main findings can be summarised as:

- A dense network of cracks has been reported to populate the interface between tantalum and molybdenum. This has been mainly caused by the mismatch in coefficient of thermal expansion between the two parent metals and by the increased brittleness of the alloy in a non-stoichiometric 35Mo-65Ta combination;

- A sharp change in the microstructural evolution was observed when depositing tungsten onto molybdenum. The main reason was the heterogeneous solidification from several nuclei with the weld pool due to the fast solidification of the weld pool;

- Variations in both composition and hardness were observed within the initial layers of the FGS between molybdenum and tungsten. It was caused by the substantial difference in melting point of the two metals and the rapid solidification characteristic of the AM processes, which did not favour the formation of a homogeneous alloy;

- The absence of cracks within the molybdenum-tungsten functionally graded structure has been reported. This has been promoted by the similarity with regard to the coefficient of thermal expansion of the two metals. This led the intermediate alloys accommodating residual stress and the cyclical expansion with minimum localization of strain.

This study proved that investigations on the influence of the process parameters as heat input and quantity of added material and on the development of a computational model would lead to allow building any controlled gradients in composition using WAAM. Furthermore, when depositing FGSs using an AM technique, not only the miscibility of the alloys and the possible formation of intermetallic or other brittle phases have to be considered, but also the possible mismatch in both thermal and mechanical properties. In particular, a pronounced mismatch with regards to the thermal properties could lead to a sudden change in the solidification regime, which can affect the microstructure, while a 
mismatch in mechanical properties could lead to failure, such as cracks, also enhanced by the residual stresses that develop when manufacturing components with by AM.

\section{Acknowledgement}

The authors wish to acknowledge financial support from the AMAZE Project, which was cofunded by the European Commission in the 7th Framework Programme (contract FP7-2012NMP-ICT-FoF-313781), by the European Space Agency and by the individual partner organisations. This work has been also part-funded by the RCUK Energy Programme [grant number EP/P012450/1].

\section{Bibliography}

[1] Reddy JN. Analysis of functionally graded plates. Int. J. Numer. Meth. Engn. 2000;47:663-684.

[2] Kawasaki A, Watanabe R. Concept and P/M fabrication of functionally gradient materials. Ceram. Int. 1997;23:73-83.

[3] Koizumi M. FGM activities in Japan. Compos. Part B Eng. [Internet]. 1997;28:1-4. Available from: http://linkinghub.elsevier.com/retrieve/pii/S1359836896000169.

[4] Niino M, Hirai T, Watanabe R. The functionally gradient materials. J. Japan Soc. Compos. Mater. 1987;13:257-264.

[5] Pareige P, Russell KF, Stoller RE, et al. Influence of long-term thermal aging on the microstructural evolution of nuclear reactor pressure vessel materials: an atom probe study. J. Nucl. Mater. 1997;250:176-183.

[6] Bernstein A, Bowden NS, Misner A, et al. Monitoring the thermal power of nuclear reactors with a prototype cubic meter antineutrino detector. J. Appl. Phys. 2008;103.

[7] Bohidar SK, Sharma R, Mishra PR. Functionally Graded Materials : A Critical Review. Int. J. Sci. Footprints. 2014;8-29.

[8] Sobczak JJ, Drenchev L. Metallic Functionally Graded Materials : A Specific Class of Advanced Composites. J. Mater. Sci. Technol. [Internet]. 2013;29:297-316. Available from: http://dx.doi.org/10.1016/j.jmst.2013.02.006.

[9] Niendorf BT, Leuders S, Riemer A, et al. Functionally Graded Alloys Obtained by Additive Manufacturing. Adv. Eng. Mater. 2014;16:857-861.

[10] Popovich VA, Borisov E V, Popovich AA, et al. Functionally graded Inconel 718 processed by additive manufacturing : Crystallographic texture, anisotropy of microstructure and mechanical properties. Mater. Des. 2017;114:441-449.

[11] Li BS, Zhao S, Hou W, et al. Functionally Graded Ti-6Al-4V Meshes with High Strength and Energy Absorption. Adv. Eng. Mater. 2016;

[12] Naebe M, Shirvanimoghaddam K. Functionally graded materials : A review of fabrication and properties. Appl. Mater. Today [Internet]. 2016;5:223-245. Available from: http://dx.doi.org/10.1016/j.apmt.2016.10.001.

[13] Sasaki M, Hirai T. Fabrication and Properties of Functionally Gradient Materials. Centen. Meml. Issue Ceram. Soc. Japan [Internet]. 1991;99:1002-1013. Available from: https://www.jstage.jst.go.jp/article/jcersj1988/99/1154/99_1154_1002/_pdf.

[14] Domack MS, Baughman JM. Development of nickel-titanium graded composition components. Rapid Prototyp. J. 2005;11:41-51.

[15] Shen C, Pan Z, Cuiuri D, et al. Fabrication of Fe-FeAl Functionally Graded Material Using the Wire-Arc Additive Manufacturing Process. Metall. Mater. Trans. B. 2016;47:763772. 
[16] Bobbio LD, Otis RA, Paul J, et al. Additive manufacturing of a functionally graded material from Ti-6Al-4V to Invar : Experimental characterization and thermodynamic calculations. Acta Mater. [Internet]. 2017;127:133-142. Available from: http://dx.doi.org/10.1016/j.actamat.2016.12.070.

[17] Carroll BE, Otis RA, Paul J, et al. Functionally graded material of 304L stainless steel and inconel 625 fabricated by directed energy deposition: Characterization and thermodynamic modeling. Acta Mater. [Internet]. 2016;108:46-54. Available from: http://dx.doi.org/10.1016/j.actamat.2016.02.019.

[18] M. Dao, Gu P, Maewal A, et al. A Micromechanical Study of Residual Stresses in Functionally Graded Materials. Acta Mater. 1996;45:3265-3276.

[19] Cannillo V, Montorsi M, Siligardi C, et al. Microscale computational simulation and experimental measurement of thermal residual stresses in glass-alumina functionally graded materials. J. Eur. Ceram. Soc. 2006;26:1411-1419.

[20] Soodi M, Masood SH, Brandt M. Thermal expansion of functionally graded and waferlayered structures produced by laser direct metal deposition. Int. J. Adv. Manuf. Technol. 2013;2011-2018.

[21] Rizakhanov RN, Polyanskii MN, Barmin a. a., et al. Functional materials for the piping of nuclear propulsion systems. Inorg. Mater. Appl. Res. [Internet]. 2014;5:124-128. Available from: http://link.springer.com/10.1134/S2075113314020178.

[22] Khripunov BI, Koidan VS, Ryazanov Al, et al. Study of tungsten as a plasma-facing material for a fusion reactor. Phys. Procedia [Internet]. 2015;71:63-67. Available from: http://dx.doi.org/10.1016/j.phpro.2015.08.313.

[23] Gumbsch P. Brittle fracture and the brittle-to-ductile transition of tungsten. J. Nucl. Mater. 2003;323:304-312.

[24] Weber T, Aktaa J. Numerical assessment of functionally graded tungsten/steel joints for divertor applications. Fusion Eng. Des. [Internet]. 2011;86:220-226. Available from: http://dx.doi.org/10.1016/j.fusengdes.2010.12.084.

[25] Brandes EA, Brook GB. Smithells Metals Reference Book. Seventh Ed. ButterworthHeinemann. Butterworth-Heinemann; 1992.

[26] Segerstark A, Andersson J, Svensson LE. Investigation of laser metal deposited Alloy 718 onto an EN 1.4401 stainless steel substrate. Opt. Laser Technol. [Internet]. 2017;97:144-153. Available from: http://dx.doi.org/10.1016/j.optlastec.2017.05.038.

[27] Carroll BE, Palmer TA, Beese AM. Anisotropic tensile behavior of Ti-6Al-4V components fabricated with directed energy deposition additive manufacturing. Acta Mater. [Internet]. 2015;87:309-320. Available from: http://dx.doi.org/10.1016/j.actamat.2014.12.054.

[28] Baufeld B, Biest O Van der, Gault R. Additive manufacturing of Ti-6Al-4V components by shaped metal deposition: Microstructure and mechanical properties. Mater. Des. [Internet]. 2010;31:S106-S111. Available from: http://dx.doi.org/10.1016/j.matdes.2009.11.032.

[29] Vilaro T, Colin C, Bartout JD, et al. Microstructural and mechanical approaches of the selective laser melting process applied to a nickel-base superalloy. Mater. Sci. Eng. A [Internet]. 2012;534:446-451. Available from: http://dx.doi.org/10.1016/j.msea.2011.11.092.

[30] Thijs L, Montero Sistiaga ML, Wauthle R, et al. Strong morphological and crystallographic texture and resulting yield strength anisotropy in selective laser melted tantalum. Acta Mater. [Internet]. 2013;61:4657-4668. Available from: http://dx.doi.org/10.1016/j.actamat.2013.04.036.

[31] Reichardt A, Dillon RP, Borgnonia JP, et al. Development and characterization of Ti-6Al$4 \mathrm{~V}$ to $304 \mathrm{~L}$ stainless steel gradient components fabricated with laser deposition 
additive manufacturing. Mater. Des. [Internet]. 2016;104:404-413. Available from: http://dx.doi.org/10.1016/j.matdes.2016.05.016.

[32] Chen SR, Gray GT. Constitutive behavior of tantalum and tantalum-tungsten alloys. Metall. Mater. Trans. A. 1996;27:2994-3006.

[33] Ding J, Colegrove P, Mehnen J, et al. Thermo-mechanical analysis of Wire and Arc Additive Layer Manufacturing process on large multi-layer parts. Comput. Mater. Sci. [Internet]. 2011;50:3315-3322. Available from: http://dx.doi.org/10.1016/j.commatsci.2011.06.023.

[34] Szost BA, Terzi S, Martina F, et al. A comparative study of additive manufacturing techniques: Residual stress and microstructural analysis of CLAD and WAAM printed Ti-6AI-4V components. Mater. Des. 2016;89:559-567. 
2019-03-11

Functionally graded structures of refractory metals by Wire Arc Additive Manufacturi

\author{
Marinelli, Gianrocco
}

Maney Publishing

Marinelli G, Martina F, Ganguly S, et al., Functionally graded structures of refractory metals by Wire Arc Additive Manufacturing. Science and Technology of Welding and Joining, Volume 24, Issue 5, 2019, pp. 495-503

https://doi.org/10.1080/13621718.2019.1586162

Downloaded from Cranfield Library Services E-Repository 